\title{
THE RESISTANCE TO DEFORMATION OF SUPERALLOYS DURING HOT ROLLING
}

\author{
E. W. Kelley \\ Stellite Division, Cabot Corporation
}

The resistance to deformation characteristics of six highperformance alloys were determined during hot rolling. Mathematical relationships are presented for these resistance-characteristics as functions of temperature and strain rate.

Superalloys are particularly resistant to deformation and their high level of resistance at elevated temperatures is one of their most useful characteristics. This however presents a challenge in the hot working of these materials into desirable product forms. The purpose of this study was to determine quantitatively the effects of temperature and strain rate on the resistance to deformation during hot rolling of certain highperformance alloys. Selected for study were HAYNES alloy No. 188, Waspaloy, and HASTELLOY alloys $\mathrm{X}, \mathrm{C}-276, \mathrm{C}-4$ and $\mathrm{B}-2$.

\section{EXPERIMENTAL PROCEDURE}

Plate of the alloys studied was obtained from production stock and cut into rolling billets nominally $100 \mathrm{~mm}$ (4 in) wide by $250 \mathrm{~mm}$ (10 in) long and $25 \mathrm{~mm}$ ( 1 in) thick. Each billet was heated in a gas-fired furnace to a selected temperature in preparation for rolling. When the billet was at temperature it was transferred to an instrumented mill and rolled. The chart drive of the instrumentation system was started at the instant the billet was taken from the furnace in order to measure the time required to transfer the billet from the furnace to the mill.

During rolling, instrumentation of the mill recorded data 
from which separating force and roll speed could be obtained. After rolling, the billet thickness, width, and length were again measured and recorded.

The experiment was repeated on each billet until the thickness had been reduced to about six millimeters (1/4 in). Various rolling drafts were used so that reductions per pass from 2 to 30 percent might be achieved. Temperatures covered the range of 850 to $1200^{\circ} \mathrm{C}$ (1560 to $2200^{\circ} \mathrm{F}$ ).

\section{Instrumentation}

A 10-inch mill was instrumented for the program. The mill has a separating force capacity of $2.45 \mathrm{MN}(550,000$ 1bs) and a roll speed of $23 \mathrm{rpm}$. Load cells between the screwdowns and chocks of the upper roll are rated at $1.11 \mathrm{MN}$ (250,000 1bs) each. A photoswitch scanning a segmented stripe on one of the roll neck wobblers was employed to generate a signal from which instantaneous roll speed could be computed.

A chart recorder was used to record the signals from the two load cells and the photoswitch, and to record the time required to transfer the hot billet from the furnace to the mill as described earlier. Furnace temperature was obtained by a recording thermocouple. With this instrumentation, data were recorded on each rolling pass that could be translated into separating force, mill face speed, furnace temperature and transit time from furnace to mill. Workpiece thickness, width and length were measured before and after each rolling pass.

\section{Temperature Determination}

Because the temperature effect is a major one, any experiment to determine the effect quantitatively must provide an accurate determination of the temperature of the workpiece at the instant it is deformed. The technique used in this study was to measure the billet temperature in the furnace, time the transfer from furnace to mill, and then use these data to calculate the temperature loss during the transfer.

The heat loss from a cooling billet is a function of the initial temperature, time, ambient temperature of the cooling medium, specific heat and thermal conductivity of the billet, surface emissivity, alloy density, and billet mass and shape. To calculate the instantaneous temperature of the billet, use was made of the one dimensional heat transfer equation: 


$$
\frac{\partial T}{\partial t}=\alpha(T) \frac{\partial^{2} T}{\partial x^{2}}
$$

and the following expression for the heal Lransfer coefficient:

$$
h=E \sigma\left(T_{\text {surf }}^{4}-T_{\text {amb }}^{4}\right) /\left(T_{\text {surf }}-T_{\text {amb }}\right)
$$

where: $\quad \mathrm{T}=$ temperature

$t=$ time

$\mathrm{x}=$ distance (within the workpiece)

$\alpha=$ thermal diffusivity $=\mathrm{K} / \rho \mathrm{C}_{\mathrm{p}}$

$\mathrm{h}=$ heat transfer coefficient

$\mathrm{E}=$ emissivity of the workpiece

$\sigma=$ radiation constant $\left(1.356 \times 10^{-12} \mathrm{cal} / \mathrm{cm}^{2}-\mathrm{s}^{\circ}{ }^{\circ} \mathrm{K}^{4}\right)$

$\mathrm{K}=$ thermal conductivity of the alloy

$\rho=$ density of the alloy

$\mathrm{C}_{\mathrm{p}}=$ specific heat of the alloy

Eq. 1 deals with conduction within the billet and Eq. 2 with radiation from the surface. The boundary conditions are:

$$
\begin{array}{ll}
\text { at } t=0 & \mathrm{~T}(\mathrm{x})=\mathrm{f}(\mathrm{x})=\mathrm{T}_{\text {furnace }} \\
\text { at } \mathrm{x}=0 & \frac{\partial \mathrm{T}}{\partial \mathrm{x}}=0 \\
\text { at } \mathrm{x}= \pm \mathrm{D} / 2 & -\mathrm{K} \frac{\partial \mathrm{T}}{\partial \mathrm{x}}=\mathrm{h}\left(\mathrm{T}_{\text {surf }}-\mathrm{T}_{\text {amb }}\right)
\end{array}
$$

where $\mathrm{x}$ is the thickness direction of a slab of thickness $\mathrm{D}$ and with origin at the slab center. At the surface the rate of heat loss to the surroundings must equal the rate that heat is conducted from the interior to the surface.

The equations were solved numerically as one dimensional heat transfer problems. Values for thermal conductivity, specif1c heat and density were taken from the literature. Values of the heat transfer coefficient were determined experimentally from instrumented billets cooling in air. For example, this coefficient for HAYNES alloy No. 188 was found to be $3.97 \times 10^{-3}$ $\mathrm{cal} / \mathrm{cm}^{2}-\mathrm{s}-{ }^{\circ} \mathrm{K}$ for cooling from an initial temperature of $1200^{\circ} \mathrm{C}$, $3.19 \times 10^{-3}$ for cooling from $1100^{\circ} \mathrm{C}$ and $2.78 \times 10^{-3}$ from $1000^{\circ} \mathrm{C}$.

With this technique, billet temperature at the instant of rolling was computed for any size billet and any initial temperature. Because the surface of a cooling billet is cooler than the interior, an average effective temperature was calcu1ated. To do this the computed temperature profile across the 
billet thickness at the end of the transfer time was integrated and divided by the thickness, in accordance with Eq. 3 .

$$
T_{\text {avg }}=\frac{1}{D / 2} \int_{0}^{D / 2} T(x, t) d x
$$

Thus, furnace temperature, transfer time, values of the thermal parameters and billet dimensions were used to compute a mean effective billet temperature for each pass at the instant the workpiece entered the roll gap.

\section{Analysis of Data}

The data obtained in the rolling experiments were converted into mill separating force, workpiece width and thickness, reduction of area, strain rate and mean effective tenperature at the instant of deformation. The resistance to deformation parameter, $k$, was then calculated for each set of rolling conditions by use of Sim's rolling equation (1):

$$
P=k b \sqrt{R} \sqrt{\Delta h} Q
$$

where: $\quad P=$ mill separating force

$\mathrm{k}=$ resistance to deformation parameter

$\mathrm{b}=$ width of workpiece

$\mathrm{R}=$ radius of the rolls

$\Delta h=$ thickness reduction in the pass

$\mathrm{Q}=$ dimensionless geometrical factor

Table 1. Q for Sim's Rolling Equation (1).

\begin{tabular}{rcccccc}
$\frac{R}{\mathrm{~h}_{2}}$ & \multicolumn{6}{c}{ Values of $Q$ for Percent Reduction of : } \\
\cline { 2 - 6 } & $\underline{5}$ & $\underline{10}$ & $\underline{15}$ & $\underline{20}$ & $\underline{25}$ & $\underline{30}$ \\
2 & .857 & .880 & .892 & .905 & .909 & .912 \\
5 & .904 & .948 & .976 & 1.003 & 1.020 & 1.037 \\
10 & .956 & 1.022 & 1.067 & 1.111 & 1.142 & 1.173 \\
20 & 1.029 & 1.127 & 1.196 & 1.264 & 1.313 & 1.362 \\
30 & 1.086 & 1.208 & 1.294 & 1.379 & 1.442 & 1.505 \\
50 & 1.175 & 1.337 & 1.450 & 1.563 & 1.644 & 1.734
\end{tabular}

where $h_{2}$ is billet thickness after the pass 
The values for $\mathrm{P}, \mathrm{b}$ and $\Delta \mathrm{h}$ were taken from the experimental data. The roll radius is, of course, a mill constant. Values for $Q$ were interpolated from Sim's empirical values reproduced in Table 1.

Regression analysis of the resulting values was employed to establish a mathematical relationship for the resistance to deformation parametcr, $k$, as a function of temperature and strain rate for each alloy studied. These relationships, given below, are considered to be accurate representations for the conditions associated with hot rolling.

\section{RESULTS}

The resistance to deformation characteristics, during hot rolling, of the six high-performance alloys studied are represented by the following relationships:

$$
\begin{aligned}
& \mathrm{k}_{188}=1715.3+261.2 \dot{\varepsilon}-1.177 \mathrm{~T}-.205 \mathrm{~T} \dot{\varepsilon} \\
& \mathrm{k}_{\text {wasp }}=1842.0+291.5 \dot{\varepsilon}-1.378 \mathrm{~T}-.228 \mathrm{~T} \dot{\varepsilon} \\
& \mathrm{k}_{\mathrm{X}}=1762.7+133.2 \dot{\varepsilon}-1.277 \mathrm{~T}-.085 \mathrm{~T} \dot{\varepsilon} \\
& \mathrm{k}_{276}=1249.6+423.5 \dot{\varepsilon}-.761 \mathrm{~T}-.343 \mathrm{~T} \dot{\varepsilon} \\
& \mathrm{k}_{\mathrm{C}-4}=1011.4+226.6 \dot{\varepsilon}-.546 \mathrm{~T}-.179 \mathrm{~T} \dot{\varepsilon} \\
& \mathrm{k}_{\mathrm{B}-2}=1.652 .4+234.9 \dot{\varepsilon}-1.064 \mathrm{~T}-.181 \mathrm{~T} \dot{\varepsilon}
\end{aligned}
$$

where: $k=$ resistance to deformation (megapascals)

$$
\begin{aligned}
& \mathrm{T}=\text { temperature (degrees Celsius) } \\
& \dot{\varepsilon}=\text { strain rate (inverse seconds) }
\end{aligned}
$$

Because of the stress conditions in the roll gap during rolling, the resistance to deformation parameter, $k$, is the plane strain yield value. Dividing the value of $k$ by $2 / \sqrt{3}$ will give the uniaxial flow stress, $\sigma_{Y}(2)$.

The above relationships are presented in graphical form in Figures 1 to 6 . These indicate that the resistance to deformation of the alloys of interest is high and is also strong1y influenced by both temperature and strain rate. The results provide a quantitative basis for predicting rolling 
luads and for establishing reduction scluedules for lot rolling the high-performance alloys.

\section{ACKNOWLEDGEMENT}

The assistance of Dr. J. H. Chen in the temperature determination portion of the study is greatly appreciated.

\section{REFERENCES}

(1) Larke, E. C., "The Rolling of Strip, Sheet and Plate," Chapman and Ha11, 1963.

(2) Backofen, W. A., "Deformation Processing," AddisonWesley, 1972.

HAYNES and HASTELLOY are registered trademarks of Cabot Corp.
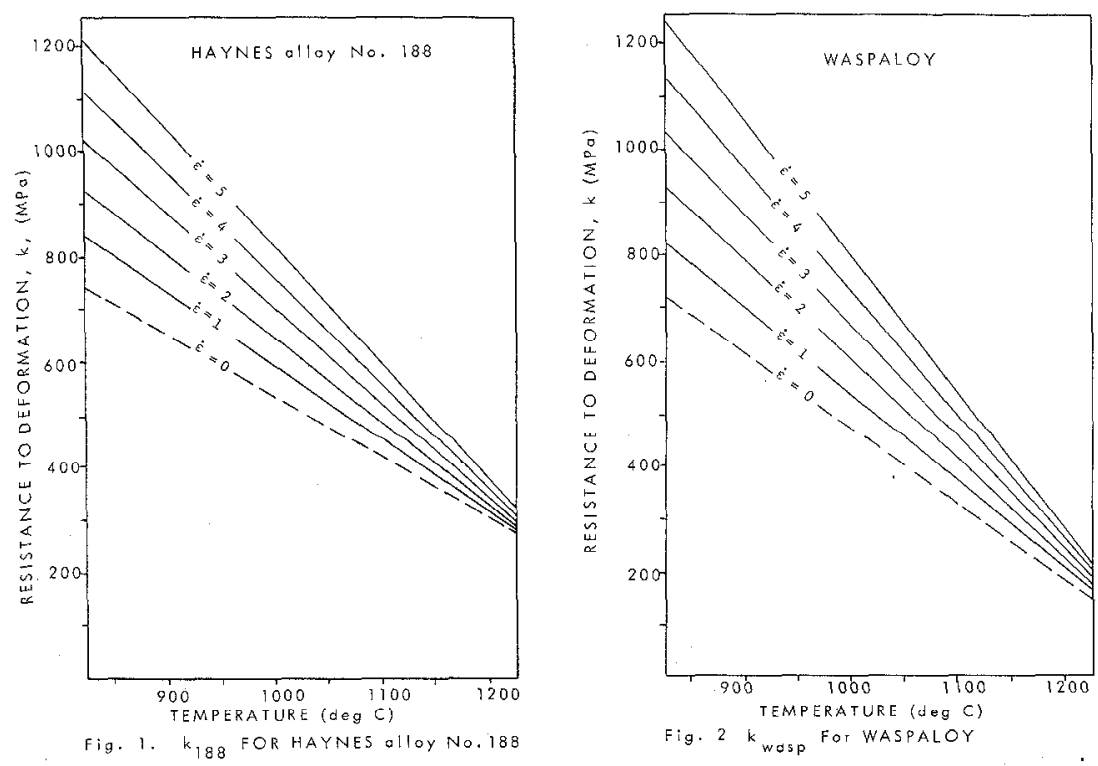


\section{E. W. Kelley / 147}

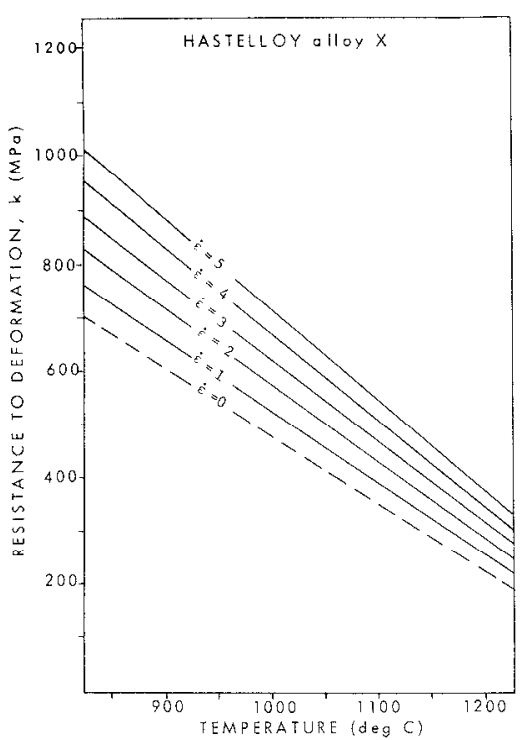

Fig. 3. $k$ For HASTELLOY olloy $X$

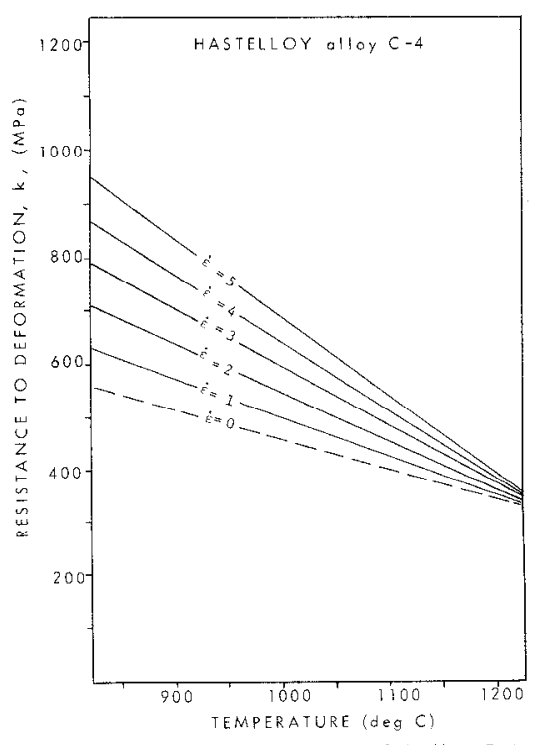

Fig. 5. ${ }^{k}$ C- 4 FOI HASTELLOY allOY $C-4$

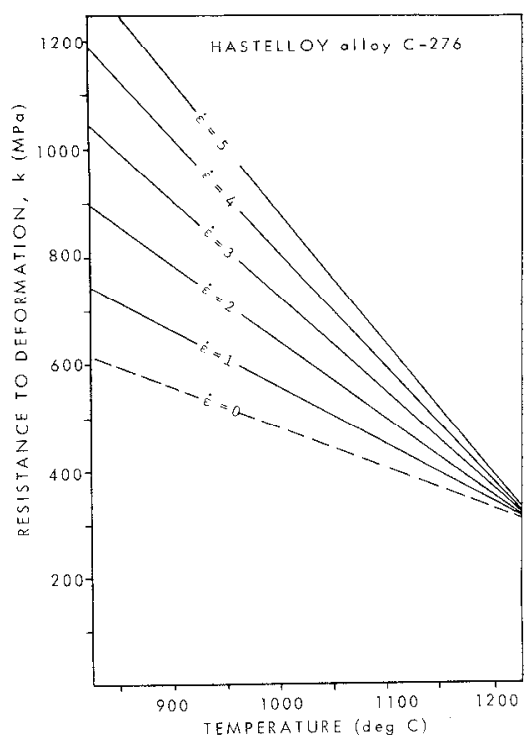

Fig. 4. $k_{276}$ FOr HASTELLOY OllOY C-276

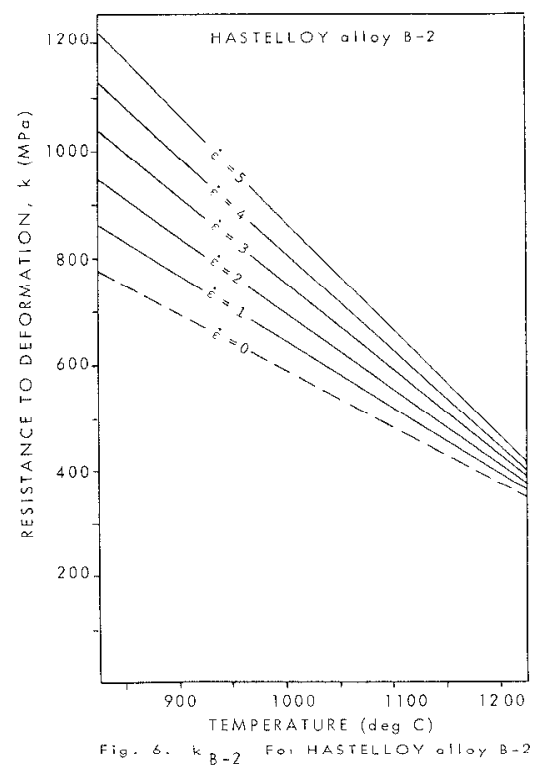

